\title{
Evaluation of bone ingrowth into porous titanium implant: histomorphometric analysis in rabbits
}

\footnotetext{
(a) Department of Oral Biosciences and Diagnosis, Faculdade de Odontologia de São José dos Campos, Unesp - Univ Estadual Paulista, São José dos Campos, SP, Brazil.

(b) Faculdade de Odontologia de São José dos Campos, Unesp - Univ Estadual Paulista, São José dos Campos, SP, Brazil.

(c)Department of Materials (AMR), Air and Space Institute (IAE), Comando-Geral de Tecnologia Aeroespacial (CTA), São José dos Campos, SP, Brazil.
}

\section{Luana Marotta Reis de \\ Vasconcellos(a) \\ Daniel Oliveira Leite ${ }^{(a)}$ \\ Fannanda Nascimento de Oliveira(b) Yasmin Rodarte Carvalho(a)
Carlos Alberto Alves Cairo(c) Yasmin Rodarte Carvalho(a)
Carlos Alberto Alves Cairo}

\section{Corresponding author:}

Luana Marotta Reis de Vasconcellos

Alameda Harvey C. Weeks, 14, sl. 09

- Vista Verde

São José dos Campos - SP - Brazil

CEP: 12223-830

E-mail: luanamrv@gmail.com

Received for publication on Jun 14, 2010 Accepted for publication on Sep 21, 2010

\begin{abstract}
A porous material for bone ingrowth with adequate pore structure and appropriate mechanical properties has long been sought as the ideal bone-implant interface. This study aimed to assess in vivo the influence of three types of porous titanium implant on the new bone ingrowth. The implants were produced by means of a powder metallurgy technique with different porosities and pore sizes: Group $1=30 \%$ and $180 \mu \mathrm{m}$; Group $2=30 \%$ and $300 \mu \mathrm{m}$; and Group $3=40 \%$ and $180 \mu \mathrm{m}$. Six rabbits received one implant of each type in the right and left tibiae and were sacrificed 8 weeks after surgery for histological and histomorphometric analyses. Histological analysis confirmed new bone in contact with the implant, formed in direction of pores. Histomorphometric evaluation demonstrated that the new bone formation was statistically significantly lower in the group G1 than in group $\mathrm{G} 3,(\mathrm{P}=0.023)$. Based on these results, increased porosity and pore size were concluded to have a positive effect on the amount of bone ingrowth.
\end{abstract}

Descriptors: Titanium; Osseointegration; Porosity; Topography, Medical.

\section{Introduction}

Titanium (Ti) and its alloys are the most frequently used materials for endosseous implants in dentistry and orthopedics due to their high degree of biocompatibility and good mechanical properties. ${ }^{1}$ Successful integration of an implant is generally accepted to rely on its surface characteristics such as chemical composition, morphology, and energy. ${ }^{2}$ Surface morphology is an important factor determining the long-term implant stability, especially when bone quality is poor. ${ }^{3}$ Porous metals have been exploited for several decades to increase friction force between the implant and bone and promote the initial and long-term stability through bone ingrowth. ${ }^{3,4,5,6}$

The advantage of porous materials is their ability to provide biological anchorage for the surrounding bone tissue via the ingrowth of mineralized tissue into the pore spaces. ${ }^{7}$ The architecture of a porous implant has been shown to substantially affect the bone ingrowth into pore space. ${ }^{5,8,9}$ Optimal pore size for bone ingrowth ranges from $100 \mu \mathrm{m}$ to $600 \mu \mathrm{m}$, and the pores must be interconnected to maintain the vascular system required for continuing bone development. ${ }^{8,9}$

Although great progress has been made in the manufacture of porous 
structures with various available fabrication processes, some limitations continue to exist. ${ }^{10}$ Several pore-generation fabrication methods have been proposed, and the technique chosen is usually dependent on the properties of the material being used. ${ }^{11}$ Current fabrication methods include the use of $\mathrm{TiH}_{2}$ suspension for reactive sintering ${ }^{12}$ or organic additives for powder metallurgy (PM), ${ }^{4,9,13,14,15}$ multiple coating, ${ }^{16}$ the tape casting ${ }^{17}$ and environmental electro-discharge sintering process. ${ }^{18}$

Based on the potential for a porous surface to enhance implant-bone contact, the purpose of this study was to evaluate the influence of pore size and porosity on bone neoformation in the use of titanium implants produced by PM technique.

\section{Material and methods Porous-surface titanium implant fabrication}

Pure Ti powder developed in the General Command of Aerospace Technology (CTA), Institute of Air and Space (IAE), Division of Materials (AMR), Brazil (purity $\geq 99.5 \%$, particle size $\leq 8 \mu \mathrm{m}$ ), was used as starting material in the present study. Urea particles (Synth ${ }^{\circledast}$, Diadema, SP, Brazil) with particle sizes from 177 to $350 \mu \mathrm{m}$ were used as spacer material. The selection of particle sizes was obtained by a screening technique. Three types of interconnected porous-surface titanium scaffolds were produced by PM. Initially, Ti powder and urea particles were mixed. The mixture was uniaxially pressed at $100 \mathrm{MPa}$ into a stainless steel mold and then pressed isostatically at $200 \mathrm{MPa}$. Next, the green specimens were heat treated at $200^{\circ} \mathrm{C}$ for $2 \mathrm{~h}$ in air to burn out the spacer particles (EDG 1800 furnace, Sonora ${ }^{\circledR}$, Campo Grande, MS, Brazil). Finally, the specimens were sintered at high temperature, $1200^{\circ} \mathrm{C}$, for $1 \mathrm{~h}$ in a vacuum $\left(10^{-7}\right.$ torr) furnace (Astro ${ }^{\circledR}$, São Paulo, SP, Brazil).

The implants were fabricated with different porosities and pore sizes by control of the quantity and size of the spacer particles added to the Ti powder:

- Group 1 (G1), porosity = 30\%, spacer particle size $=180 \mu \mathrm{m}$;

- Group 2 (G2), porosity $=30 \%$, spacer particle size $=300 \mu \mathrm{m} ;$ and
- Group 3 (G3), porosity $=40 \%$, spacer particle size $=180 \mu \mathrm{m}$.

After sintering, the porous-surface titanium implants had an average diameter and length of $4 \mathrm{~mm}$ with pores located only on the specimen surface and a solid core aimed to optimize the mechanical properties of the specimens (Figure 1).

\section{Animal experiments}

Six New Zealand albino rabbits aged 4-6 months and with a mean weight of $4.0 \mathrm{~kg}$ were used in this study. The rabbits were provided by the Animal Center of the São José dos Campos School of Dentistry, kept in individual cages and fed with commercial food (Coelhil $\mathrm{R}^{\circledR}$ - Socil, Belo Horizonte, MG, Brazil) and water ad libitum. The rabbits received one specimen of each type (G1, G2, G3) in the left and right tibiae. This study was approved by the Ethics in Research Committee of the Graduate School of Dentistry of São José dos Campos, UNESP (021/2005).

Before surgery, the rabbits were weighed and intramuscularly anesthetized with a mixture of $13 \mathrm{mg} /$ $\mathrm{kg}$ aqueous solution of 2\% 2-(2,6-xylidine)-5,6dihydro-4H-1,3-thiazine hydrochloride (Rompun $^{\circledR}$ Bayer, São Paulo, SP, Brazil), an analgesic, sedative, and muscle relaxant substance, and $33 \mathrm{mg} / \mathrm{kg}$ ketamine (Dopalen ${ }^{\circledR}$, Agibrands do Brazil Ltda., São Paulo, SP, Brazil), a general anesthetic. A local anesthetic composed of $3 \%$ octapressin combined with

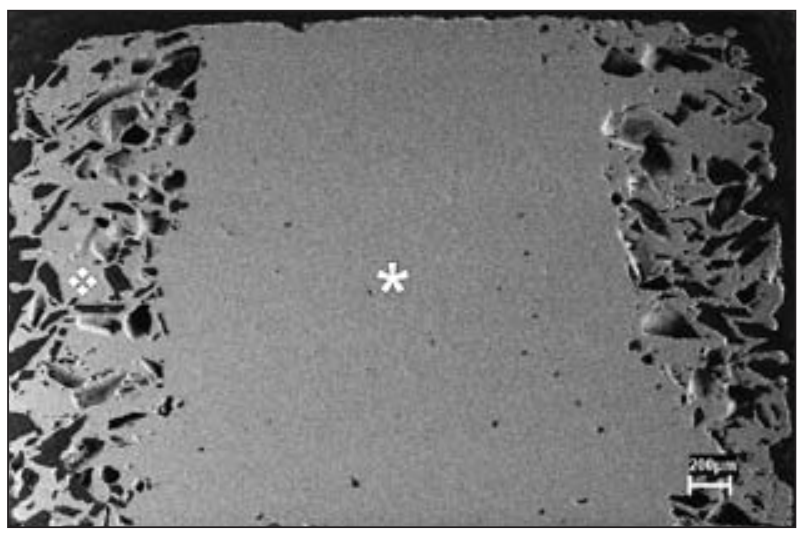

Figure 1 - SEM micrograph of a longitudinal section: porous-surface $(*)$ titanium implant with solid core $(\boldsymbol{*})$ fabricated by a powder metallurgy technique, with original magnification of $20 X$. 
prilocaine hydrochloride and felypressin (3\% Citanest, Dentsply ${ }^{\circledR}$, Petrópolis, RJ, Brazil) was also used.

The procedures were performed under standard sterile conditions. After hair removal, shaving, disinfection, and draping, a straight 3-cm skin incision was made over the medial portion of both tibiae. Three perforations of $4 \mathrm{~mm}$ in diameter were made bilaterally at $0.5 \mathrm{~cm}$ intervals using an electric surgical drill (AEU707Av2, Aseptico, Washington USA). During drilling, the drill was continuously cooled with saline. Just before insertion of the implants, the hole was irrigated with saline to remove any bone shards.

One specimen of each type was placed into one perforation on each tibia and pressed into the surgical cavity until it was fixed to the cortical bone. The muscle tissue and skin were sutured with mononylon 4-0 surgical thread (Johnson \& Johnson, São José dos Campos, SP, Brazil). The rabbits received one injection of Pentabiotico ${ }^{\circledR}$ (Fort Dodge Saúde Animal, São Paulo, SP, Brazil) after the surgery and were then inspected daily for clinical signs of complications or adverse reactions. The rabbits were sacrificed 8 weeks after surgery by intramuscular injection of a high dose of the anesthetic solution.

\section{Histological and histomorphometric examination}

Six animals were prepared for histological analysis. Implant-containing bone fragments were fixed in $10 \%$ formalin for $48 \mathrm{~h}$ and subjected to serial alcohol dehydration for $24 \mathrm{~h}$ each. The fragments were then embedded in xylol (Synth ${ }^{\circledR}$, Diadema, SP, Brazil) for 3 days, followed by methyl methacrylate resin (Synth ${ }^{\circledR}$, Diadema, SP, Brazil). Next, they were sectioned longitudinally with a low speed diamond saw (Labcut 1010, Extec Corp ${ }^{\circledR}$, Enfield, CT, USA) in serial sections of $400 \mu \mathrm{m}$ and ground to a thickness of $50 \mu \mathrm{m}$ in a polishing machine (Labpol 8-12, Extec Corp ${ }^{\circledR}$, Enfield, CT, USA). Microscopic analyses were performed using an optical microscope (Axion Vision 3.1, MO, Carl Zeiss, Germany) attached to a digital camera (DSC-S85 Cybershot, Sony Brasil Ltda., Manaus, AM, Brazil) and with scanning electron microscopy (Leo, SEM, Leo Ldta., Cambridge, UK).
In the histomorphometric analysis, the percentage of new bone at the bone-implant interface was evaluated in two sections of each implant. Two fields of each section were digitized (100x), representing the medial and distal interface of the implant. For standardization, the images for histomorphometric analysis were taken in the same position, previously standardized on a television monitor (TC-L32C Viera, Panasonic Brasil Ltda., Manaus, AM, Brazil), attached to the equipment. Thus, 48 sections per region were evaluated in the histomorphometric analysis. The amount of new bone and bone ingrowth to the interior of the pores was calculated using image processing software (Image J, Microsoft Java1.4, Maryland, USA) as a percentage of total bone-implant interface area. Statistical analyses were performed on the histomorphometric results using one-way ANOVA followed by a post hoc test (Tukey multiple comparison test) with $\mathrm{P}<0.05$ to determine differences between implant conditions.

\section{Results Histological examination}

All the rabbits presented satisfactory postoperative results, with no evidence of inflammation or infection at the surgical site. No adverse reaction was observed during the procedure.

Regardless of the type of specimen, new bone was observed at the implant-bone interface, leading to osseointegration, and new bone was also observed growing into the pores (Figures 2 and 3). This new bone consisted of mature bone trabeculae that presented lamellar arrangement and different-sized medullar spaces. Bone ingrowth into the pores was observed in all rabbits, even deep inside the more internal pores (Figure 3). In general, smaller pores were totally filled with bone, whereas bigger pores were partially filled (Figure 4). A distinct border occurred between newly formed bone and preexisting bone (Figure 5). New bone was also observed both above (Figure 2) and below the implants, and the pores in these areas also presented new bone.

\section{Histomorphometric examination}

The bone ingrowth rates are presented in table 1 . Group 1 (25.64\%) presented the lowest quantity of 


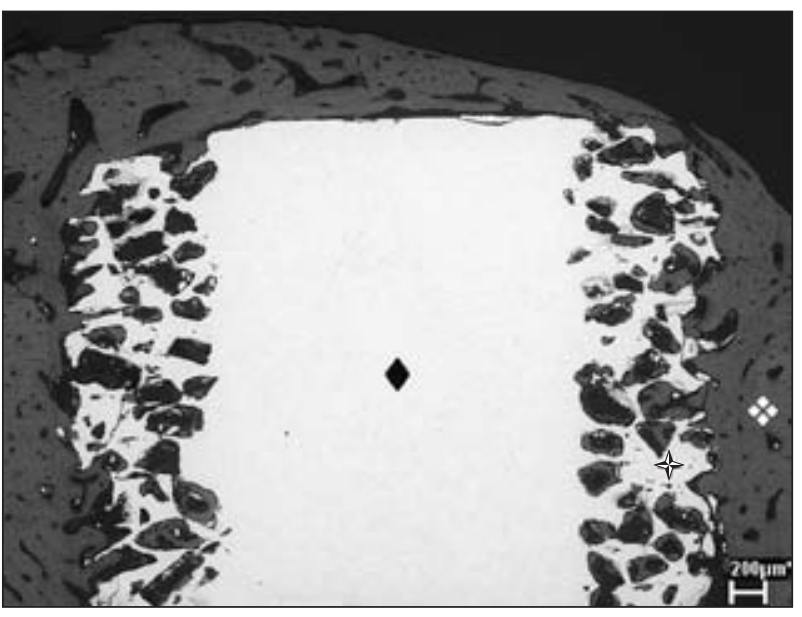

Figure 2 - SEM micrograph of the bone-implant interface: osseointegration and new bone $(*)$, bone ingrowth in porous-surface titanium specimen $(\star)$, solid core $(\bullet)$, with original magnification of $25 \mathrm{X}$.

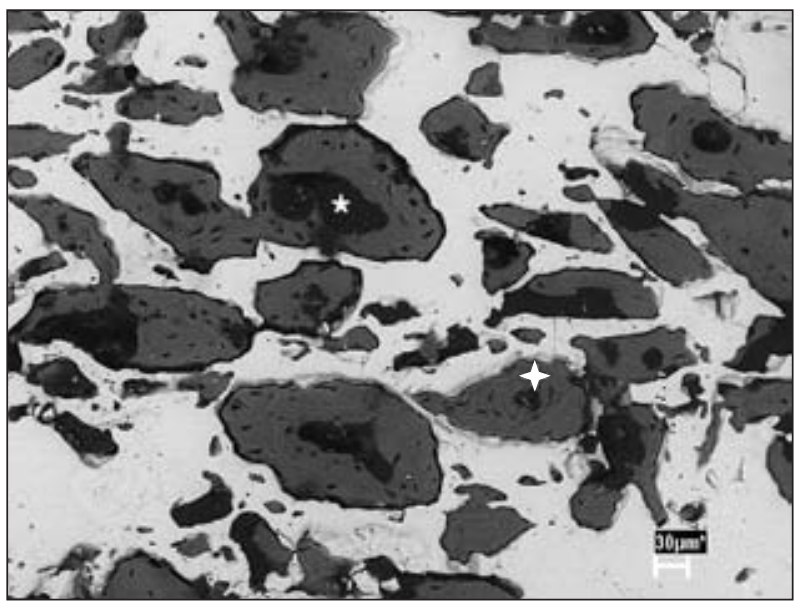

Figure 4 - SEM micrograph of the smaller pores totally filled with bone $(*)$, whereas bigger pores were partially filled with bone and resin $(\star)$, with original magnification of 200X.

new bone and Group $3(30.31 \%)$ showed the greatest quantity of new bone, with a statistically significant difference observed between the two implant types $(\mathrm{P}=0.023)$. No difference between Groups 2 and 3 was observed.

\section{Discussion}

Implant surface properties have a direct role in osteogenesis at the bone-implant interface, influencing a series of coordinated events including protein adsorption, cell proliferation, and bone tissue depo-

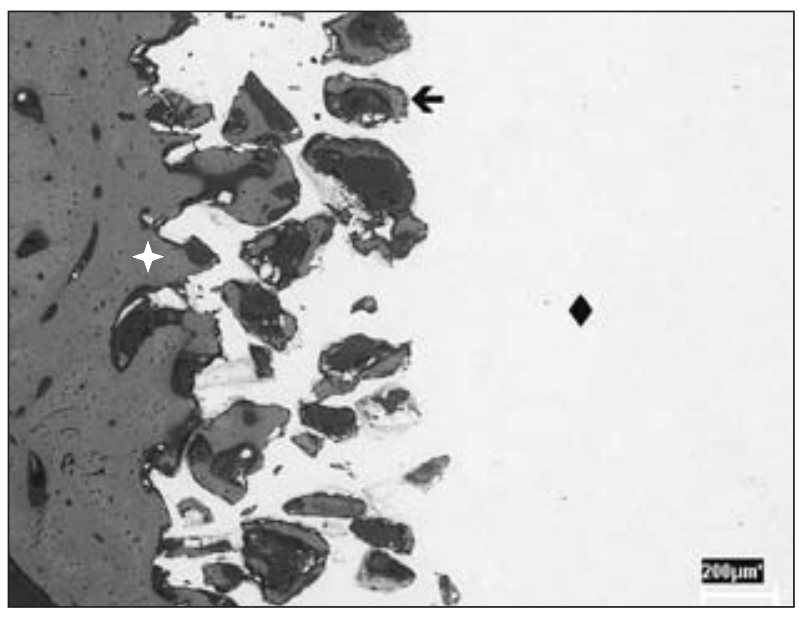

Figure 3 - SEM micrograph of bone ingrowth into the pores $(\star)$, even deep inside the more internal pores (4) and near the solid core $(\bullet)$, with original magnification of $150 \mathrm{X}$.

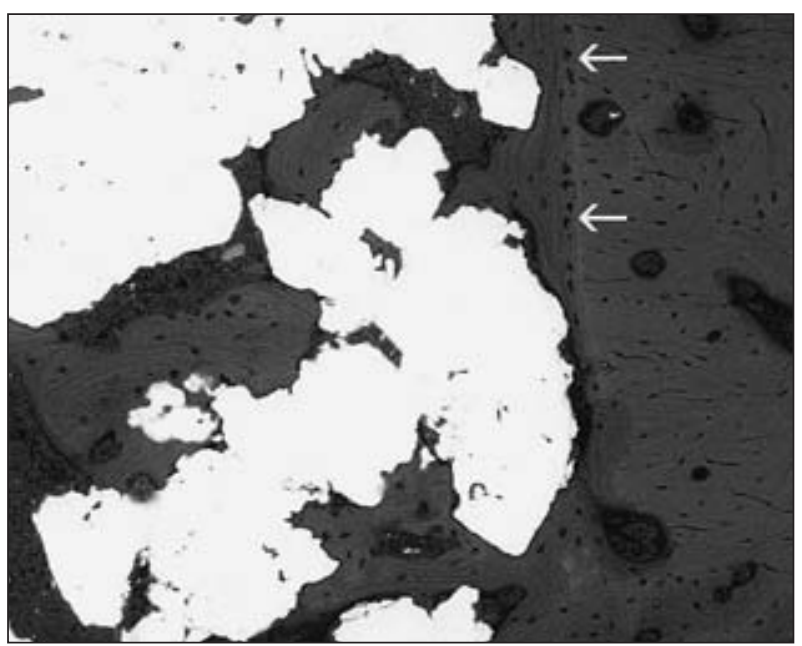

Figure 5 - SEM micrograph of the bone-implant interface: delimitation between newly formed bone and preexisting bone $(\leftarrow)$, with original magnification of 400X.

sition. ${ }^{4}$ Therefore, many efforts to modify the titanium implant surface for improved tissue response have been reported. ${ }^{19,20,21}$ The advantage of porous materials is their ability to provide biological anchorage for surrounding bone tissues ${ }^{18,22}$ and greater contact area at the implant-bone interface. ${ }^{4,9}$ Additionally, the bone-filled porous structure is a composite, an important area of transition between the titanium core and bone. ${ }^{8}$

The influence of porosity, pore size, and spatial arrangement on the biological behavior of bone has 
Table 1 - Histomorphometry: percentage of new bone formation at the bone-implant interface.

\begin{tabular}{c|c|c|c}
\hline $\begin{array}{c}\text { Observation } \\
\text { period }\end{array}$ & Implant & $\begin{array}{c}\text { Histomorphometry } \\
\text { Mean } \pm \text { SD (\%) }\end{array}$ & P value \\
\hline \multirow{3}{*}{8 weeks } & G1 & $25.64 \pm 2.36$ & \\
\cline { 2 - 3 } & G2 & $29.13 \pm 1.43$ & \multirow{2}{*}{0.023} \\
\cline { 2 - 3 } & $\mathrm{G} 3$ & $30.31 \pm 3.84$ & \\
\hline
\end{tabular}

been investigated in several studies. ${ }^{8,9,14,15}$ Changes in pore shape can also radically affect the success of bone development; the optimal morphogenetic geometry for bone ingrowth has a concave shape with specific dimensions. ${ }^{23,24} \mathrm{New}$ bone growth into porous metal implants also depends on factors, including interconnecting pore size, ${ }^{7,25}$ pore throats open to the surface, ${ }^{8}$ and the presence of gaps between the implant and bone surface. ${ }^{7}$ However, no consensus has yet been reached regarding optimal pore structure.

The optimal pore size for bone ingrowth has been reported to range from 150 to $600 \mu \mathrm{m}$. In the present study, the pore sizes of implants evaluated were between the lower and upper limits of this optimal range for porous materials. Data indicate that scaffolds with the smallest pore size and lowest porosity had significantly less bone ingrowth. Thus, pore size, porosity, and interconnected pore size can all affect osteoconductivity. ${ }^{5,7,26}$ Although increased porosity and pore size are clearly preferential for new bone growth facilitation in $\mathrm{Ti}$ implants, it should be kept in mind that another consequence of increased porosity and pore size is a reduction in the mechanical properties of the implant. Thus, depending on the intended application, a balance between mechanical properties and biological performance should be established.

The pores must be connected to maintain the vascular system required for continuing bone development. A three-dimensional open porous structure is particularly suitable for implant fixation by tissue ingrowth. ${ }^{26}$ Pore interconnection is believed to be critical for the proliferation of bone tissue, since different networks can affect bone ingrowth or tissue differentiation in each pore, but its influence is not yet well understood. All porosity parameters will affect or compromise cell proliferation and differentiation within the pores to different degrees, and, since bone ingrowth invades the porous structure from the periphery towards the center, short routes should be considered important. ${ }^{8}$ In this study, implants were developed with solid cores and porous surfaces; therefore the pores were restricted to the surface of the implant, a characteristic that should help to fill the entire pore by bone tissue since the routes were all short.

Traditionally, two-dimensional image analyses have been used to quantify the amount of bone in pores and evaluate bone-implant contact by measuring contact between the two phases (i.e., Ti and bone) with optical or radiographic techniques or SEM. ${ }^{15}$ In this study, microscopic analysis was performed using optical microscopy and SEM. Histomorphometric analysis revealed that Group 1 obtained significantly less bone ingrowth. This occurred as a consequence of the implant structure, which presented smaller pores and lower porosity, thereby decreasing the space for bone growth in this group. In contrast, Group 2 and 3 implants exhibited an increased area of porous Ti compared with Group 1 implants. These data suggest that, for the implants investigated in the present study, bone conduction is definitely influenced by pores and porosity.

The use of Ti associated with different concentrations and sizes of urea granules permitted the fabrication of implants with well-controlled porous structures, i.e., control of porosity, pore size, and spatial arrangement. Such control over specimen architecture permits the investigation of how geometric parameters influence biological performance of biomaterials, such as osseointegration. In this study, the occurrence of a distinct border was noted between newly formed and preexisting bone, emphasizing the biocompatibility of the material as an appropriate surface for new bone proliferation.

Porous titanium implants have not yet been applied in dentistry. Indeed, few technologies allow the fabrication of this surface in implants as small as dental implants. ${ }^{15}$ However, a smaller segment 
of porous implant allows for more effective contact with the bone, due to the relatively greater contact area determined by its topography. 9,25

This study sought to demonstrate the capacity for the production of porous-surface titanium while controlling pore size, percentage, and distribution using a powder metallurgy technique. The versatility of manufacturing implants with a solid core and different types of porous surface permits the development of implants that produce distinct rates of bone tissue proliferation. Given the positive results obtained, future studies can focus on determining the specific parameters required to develop implants for use in clinical applications.

\section{References}

1. Albrektsson T, Branemark PI, Hansson HA, Lindstrom J. Osseointegrated titanium implants. Requirements for ensuring a long-lasting, direct bone-to-implant anchorage in man. Acta Orthop Scand. 1981 Jan;52(1):155-70.

2. Brunski JB, Puleo DA, Nanci A. Biomaterials and biomechanics of oral and maxillofacial implants: Current status and future developments. Int J Oral Maxillofac Implants. 2000 Jan-Feb;15(1):15-46.

3. Pilliar RM, Cameron HU, Macnab I. Porous surface layered prosthetic devices. Biomed Eng. 1975 Apr;10(4):126-31.

4. Rosa AL, Crippa GE, Oliveira PT, Taba Jr M, Lefebvre L-P, Beloti MM. Human alveolar bone cell proliferation, expression of osteoblastic phenotype, and matrix mineralization on porous titanium produced by powder metallurgy. Clin Oral Implants Res. 2009 May;20(5):472-81.

5. Li JP, Habibovic P, Doel MVD, Wilson CE, Wijn JR, Blitterswijk CA, Groot K. Bone ingrowth in porous titanium implants produced by 3D fiber deposition. Biomaterials. 2007 Jun;28(18):2810-20.

6. Pilliar RM. Overview of surface variability of metallic endosseous dental implants: textured and porous surface-structured designs. Implant Dent. 1998 Apr;7(4):305-14.

7. Simmons CA, Valiquete N, Pilliar RM. Osseointegration of sintered porous-surfaced and plasma spray-coated implants: an animal model study of early postimplantation healing response and mechanical stability. J Biomed Mater Res. 1999 Nov;47(2):127-38.

8. Otsuki B, Takemoto M, Fujibayashi S, Neo M, Kokubo T, Nakamura T. Pore throat size and connectivity determine bone and tissue ingrowth into porous implants: three-dimensional micro-CT based structural analyses of porous bioactive titanium implants. Biomaterials. 2006 Dec;27(35):5892-900.

\section{Conclusion}

According to the specific model used in this study, it can be concluded that the bone ingrowth into porous titanium implants demonstrated distinct biological behaviors varying with pore size and porosity. Increased porosity and pore size showed a direct positive effect on the amount of new bone growth.

\section{Acknowledgment}

This study was supported by research grant 2005/03709-4, awarded by the State of São Paulo Research Foundation (FAPESP), Brazil.

9. Vasconcellos LMR, Oliveira MV, Graça MLA, Vasconcellos LGO, Cairo CAA, Carvalho YRC. Design of dental implants, influence on the osteogenesis and fixation. J Mater Sci Mater Med 2008 Aug;19(8):2851-7.

10. Ryan G, Pandit A, Apatsidis DP. Fabrication methods of porous metals for use in orthopaedic applications. Biomaterials 2006 May;27(13):2651-70.

11. Capes JS, Ando HY, Cameron RE. Fabrication of polymeric scaffolds with a controlled distribution of pores. J Mater Sci Mater Med. 2005 Dec;16(12):1069-75.

12. Cachinho SCP, Correia RN. Titanium porous scaffolds from precursor powders rheological optimization of $\mathrm{TiH}_{2}$ slurries. Powder Technol. 2007 Sep;178(3):111-5.

13. Garcia Barriocanal J, Pérez P, Garcéz G, Adeva P. Microstructure and mechanical properties of $\mathrm{Ni}_{3} \mathrm{Al}$ base alloy reinforced with $\mathrm{Cr}$ particles produced by powder metallurgy. Intermetallics. 2006 May;14(5):456-63.

14. Brentel AS, Vasconcellos LMR, Oliveira MV, Graça MLAG, Vasconcellos LGO, Cairo CAA, et al. Histomorphometric analysis of pure titanium implants with porous surface versus rough surface. J Appl Oral Sci. 2006 Jun;14(3):213-8.

15. Wazen RM, Lefevre L-P, Baril E, Nanci A. Initial evaluation of bone ingrowth into a novel porous titanium coating. J Biomed Mater Res B Appl Biomater. 2010 Mar;94(1):64-71.

16. Li JP, Li SH, Van Bliterswijk CA, De Groot K. Cancellous bone from porous $\mathrm{Ti}_{6} \mathrm{Al}_{4} \mathrm{~V}$ by multiple coating technique. $\mathrm{J}$ Mater Sci Mater Med. 2006 Feb;17(2):179-185.

17. Rak ZS, Walter J. Porous titanium foil by tape casting technique. J Mater Process Technol. 2005 Jun;175(1-3):358-63.

18. An YB, Lee WH. Synthesis of porous titanium implants by environmental-electro-discharge-sintering process. Mater Chem Phys. 2006 Feb;95(2-3):242-7. 
19. Faeda RS, Tavares HS, Sartori R, Guastaldi AC, Marcantonio Jr E. Evaluation of titanium implants with surface modification by laser beam. Biomechanical study in rabbit tibias. Braz Oral Res. 2009 Apr-Jun;23(2):137-43.

20. Alves SF, Wassall T. In vitro evaluation of osteoblastic cell adhesion on machined osseointegrated implants. Braz Oral Res. 2009 Apr-Jun;23(2):131-6.

21. Park J-W, Jang II-S, Suh J-Y. Bone response to endosseous titanium implants surface-modified by blasting and chemical treatment. A histomorphometric study in the rabbit femur. J Biomed Mater Res B Appl Biomater. 2008 Feb;84(2):400-7.

22. Thelen S, Barthelat F, Brinson LC. Mechanics considerations for microporous titanium as an orthopedic implant material. J Biomed Mater Res. 2004 Jun 15;69(4):601-10.
23. Ripamonti U. Soluble, insoluble and geometric signals sculpt the architecture of mineralized tissues. J Cell Mol Med. 2004 April-Jun 8(2):169-80.

24. Ripamonti U. Osteoinduction in porous hydroxyapatite implanted in heterotopic sites of different animal models. Biomaterials. 1996 Jan;17(1):31-5.

25. Branemark PI. Osseointegration and its experimental background. J Prosthet Dent. 1983 Sep;50(3):399-410.

26. Li JP, Li SH, Van Blitterswijk CA, Groot de K. A novel porous Ti6Al4V: characterization and cell attachment. J Biomed Mater Res A. 2005 May 1;73(2):223-33. 